\title{
The Differential Diagnosis of Adult Onset Metachromatic Leukodystrophy and Early Onset Familial Alzheimer Disease in an Alzheimer Clinic Population
}

\author{
A.D. Sadovnick, H. Tuokko, D.A. Applegarth, J.R. Toone, T. Hadjistavropoulos and B.L. Beattie
}

\begin{abstract}
Clinical differentiation between forms of progressive dementia can prove difficult, particularly when relatively rare forms of dementia are involved. Factors such as family history of dementia, age at onset, presenting features such as personality change, cognitive deficits, psychiatric symptoms, and clinical course (progressive deterioration; retention of skills over time) may prove useful for directing investigations to identify underlying pathology and genetic implications. This is illustrated by two patient reports. Each patient had the onset of memory/behavioral problems at approximately age 40 years, was initially given a psychiatric, non-dementing diagnosis, and had a positive family history for early onset behavioral and memory problems. After longitudinal assessment, the diagnosis of Alzheimer disease was confirmed at autopsy in one patient and a diagnosis of familial, adult-onset metachromatic leukodystrophy in the other.
\end{abstract}

RÉSUMÉ: Diagnostic différentiel de la leucodystrophie métachromatique de l'adulte et de la maladie d'Alzheimer familiale dans une clinique d'Alzheimer. Il peut être difficile de différencier cliniquement les formes progressives de démence, particulièrement quand il s'agit de formes relativement rares. Des facteurs comme une histoire familiale de démence, l’âge de début, les manifestations initiales, telles les changements de personnalité, les déficits cognitifs, les symptômes psychiatriques, et l'évolution clinique (la détérioration progressive, la préservation à travers l'évolution de certaines habiletés) peuvent s'avérer utiles pour orienter l'investigation dans le but d'identifier la pathologie sous-jacente et les implications génétiques. Nous rapportons deux cas qui illustrent ce fait. Les problèmes de mémoire/de comportement ont commencé vers l'âge de 40 ans chez chacun des deux patients, tous les deux ont reçu un diagnostic psychiatrique ne comportant pas de démence et avaient une histoire familiale positive de problèmes précoces de comportement et de mémoire. A la suite d'une évaluation longitudinale, le diagnostic de maladie d'Alzheimer a été confirmé à l'autopsie chez un patient et un diagnostique de leucodystrophie métachromatique de l'adulte chez l'autre.

Can. J. Neurol. Sci. 1993; 20:312-3/8

The differential diagnosis for dementia is always an issue, especially when the disease onset is at a young age, late 30's, early 40's. Alzheimer disease (AD) was first described in a 51year-old woman with progressive deterioration in cognitive functioning who, at autopsy, showed senile plaques and neurofibrillary tangles throughout the cerebral cortex. ${ }^{2}$ Although Alzheimer did not comment on the family history of this woman, it is now recognized that a portion of $\mathrm{AD}$ patients, especially those with very early onset (ages in the 40 s and 50 s), may have a purely genetic etiology ${ }^{3}$ constituting familial Alzheimer's disease (FAD).

Another etiology for progressive dementia in relatively young individuals can be adult onset metachromatic leukodystrophy (MLD). MLD results from a deficiency of arylsulphatase
$A$ and is characterized by demyelination of the central and peripheral nervous systems selectively affecting the myelinated axons but sparing the cortical and subcortical grey matter. Adult forms of MLD usually present with dementia and/or psychiatric disturbance. Recently, a 38-year-old male was reported with isolated peripheral neuropathy. ${ }^{4}$ Age of clinical manifestation for adult onset MLD ranges from 16 to 63 years. ${ }^{5.6}$ As with many lysosomal storage diseases, MLD shows clinical heterogeneity that may reflect genetic heterogeneity. A pseudodeficiency allele allowing homozygous individuals to synthesize enough arylsulphatase $A$ to prevent clinically apparent disease has been analyzed. ${ }^{7}$ Polten et al. ${ }^{8}$ subsequently described 4 genotypes that are combinations of two arylsulfatase A alleles that cause MLD

From the Departments of Medical Genetics (A.D.S.), Psychiatry (H.T.), Paediatrics (D.A.A., J.R.T.) and Psychology (T.H.), University of British Columbia and Clinic for Alzheimer Disease and Related Disorders, University Hospital-UBC Site (A.D.S., H.T., T.H., B.L.B.), Vancouver

Received February 3, 1993. Accepted in final form July 22, 1993

Reprint requests 10: Dr. A.D. Sadovnick, Department of Medical Genetics, University of British Columbia, \#226-2174 University Boulevard, Vancouver, British Columbia V6T 1Z3 
and the pseudodeficiency allele. These genotypes are associated with different levels of residual arylsulphatase A activity - ranging from $0-10 \%$ - and represent the clinical spectrum from the most severely affected children to healthy adults.

The diagnosis of adult onset MLD is often initially overlooked in clinical practice, even when symptoms of a dementing or psychotic illness associated with white matter disease present in a relatively young individual. In addition, measurement of arylsulphatase $\mathrm{A}$ is not routinely done in most, if not all, Alzheimer/dementia "clinics/centres".

Although individual reports of early onset $\mathrm{AD}^{9}$ and adult onset metachromatic leukodystrophy ${ }^{10}$ are abundant in the literature, to the best of our knowledge, there has not been a systematic comparison of these two disorders. This paper will compare the clinical presentation of degenerative disorders involving cortical (FAD) and white matter (MLD) pathology. Implications of these diagnoses with respect to prognosis (clinical, neuropsychological) and familial risks will be discussed.

\section{Clinic for Alzheimer Disease and Related Disorders ("Alzheimer Clinic")}

The Clinic for Alzheimer Disease and Related Disorders at the University Hospital-UBC Site ("Alzheimer Clinic") has a multidisciplinary approach to the assessment for dementia. Each patient is assessed by a neurologist, internist/geriatrician, neuropsychologist and social worker. In addition, each consecutive unrelated patient (index patient) has a detailed family history taken and documented by a geneticist." Routine laboratory tests administered include a complete blood count, erythrocyte sedimentation rate, $\mathrm{B} 12$, serum folate, sodium, potassium, blood urea nitrogen, creatinine, fasting blood sugar, total bilirubin, calcium, phosphate, uric acid, alkaline phosphatase, lactate dehydrogenase, total protein, albumin, cholesterol, thyroid stimulating hormone and syphilis serology. Additional routine diagnostic procedures include a CT scan of the head, chest x-ray and electrocardiogram. A detailed battery of neuropsychological tests is given and includes (i) the Multi-focus Assessment Scale (MAS) which measures social behaviour, auditory and visual receptive language skills, expressive language skills, orientation, mood and accessibility for testing; ${ }^{12}$ (ii) the Wechsler Adult Intelligence Scale (WAIS), Digit Span, Similarities, Digit Symbol and Block Design subscales; age-corrected scaled scores; ${ }^{13}$ (iii) the Controlled Oral Word Association Test or Word Fluency test which measures the ability to generate words in response to stimulus letters; ${ }^{14}$ (iv) Finger Tapping Test and Dynamometer, measures of fine motor speed and grip strength; (v) Item 227 (Visual Recall) from the Luria Nebraska Neuropsychological Battery (LNNB), modified to include copy and delayed recall components; ${ }^{15}$ and the Cued Recall procedure for memory assessment. ${ }^{16-18}$

\section{Patient Reports \\ Patient I}

Patient 1, born in 1940, was a high school graduate and worked both as an announcer and a salesman for a radio station. He was well until age 40 when he became disoriented to date and destination while travelling. Subsequently, he had increasing problems with his job including repetitiveness and the loss of his ability to "ad lib" during live radio broadcasts. By age 44 , he could no longer work and had to stop driving.

He initially presented to the Alzheimer Clinic in April 1985 with a diagnosis of "unipolar depression" and "pseudodementia" caused by anxiety because of a strong family history of AD (see Figure 1).

Patient I's family has been described in detail previously ${ }^{9}$ and is

\section{Key to Pedigrees}

Index Patient (Proband)

Male

Female

Deceased

Autopsy Confirmed FAD (Figure 1)

Clinical Diagnosis of FAD (Figure 1)

Metachromatic Leukodystropy (Figure 2)

Married

Siblings

Monozygotic Twins

believed to represent early onset FAD. Eleven affected family members ( 6 females; 5 males) in 4 generations were initially described and a twelfth patient (female) has since been diagnosed (individual IV-4 in Figure 1). The diagnosis of $\mathrm{AD}$ had been confirmed on neuropathology for several family members - see Figure 1.

At initial assessment, no major medical problems were identified in Patient 1. He was living at home and was able to do household chores. He was fully oriented, cooperative and pleasant. Receptive and expressive language skills were unimpaired. His laboratory screen for dementia was negative. A CT head scan showed only mild cerebral atrophy but Positron Emission Tomography (PET) scanning revealed a pattern typical for Alzheimer disease with reduced glucose utilization in the parietal and temporal lobes. Patient 1 was reassessed in 1986 by which time neuropsychological examination showed progressive memory loss, apraxia, aphasia and difficulty with abstract reasoning. One year later. Patient 1 was still living at home, but his spouse had stopped working in order to care for him. He was hostile, agitated, and aggressive. He was disoriented with respect to time and place, had marked expressive language deficits and could not comprehend simple oral or written instructions. On neurological examination, limb apraxia and primitive reflexes were noted. Active hand tremors and jerky arm movements were also observed (probably action myoclonus). Table I summarized the neuropsychological test results over time for Patient 1.

Approximately 10 days after this final assessment, Patient 1 had an episode of aggressive and uncontrollable behaviour and was placed in a high security psychiatric institution. He died in 1988. Neuropathology confirmed the diagnosis of AD. Linkage studies and the establishment of cell lines were unsuccessful because of laboratory-related difficulties.

\section{Patient 2}

Patient 2, born in 1941, had a grade 8 education. He worked seasonally as a fisherman. Although noted by his family to be "lazy", he was said to be a capable fisherman who capably handled boats and fishing rigging. Patient 2 married in 1967 but divorced in 1981. At that time, a change in his behaviour was noticed. He became increasingly irresponsible with money, hygiene and chores, showed progressive confusion and lacked concentration. He would wander away from home without purpose or destination. At times, his behaviour was socially inappropriate (e.g., making bird calls while others were engaged in conversation). 


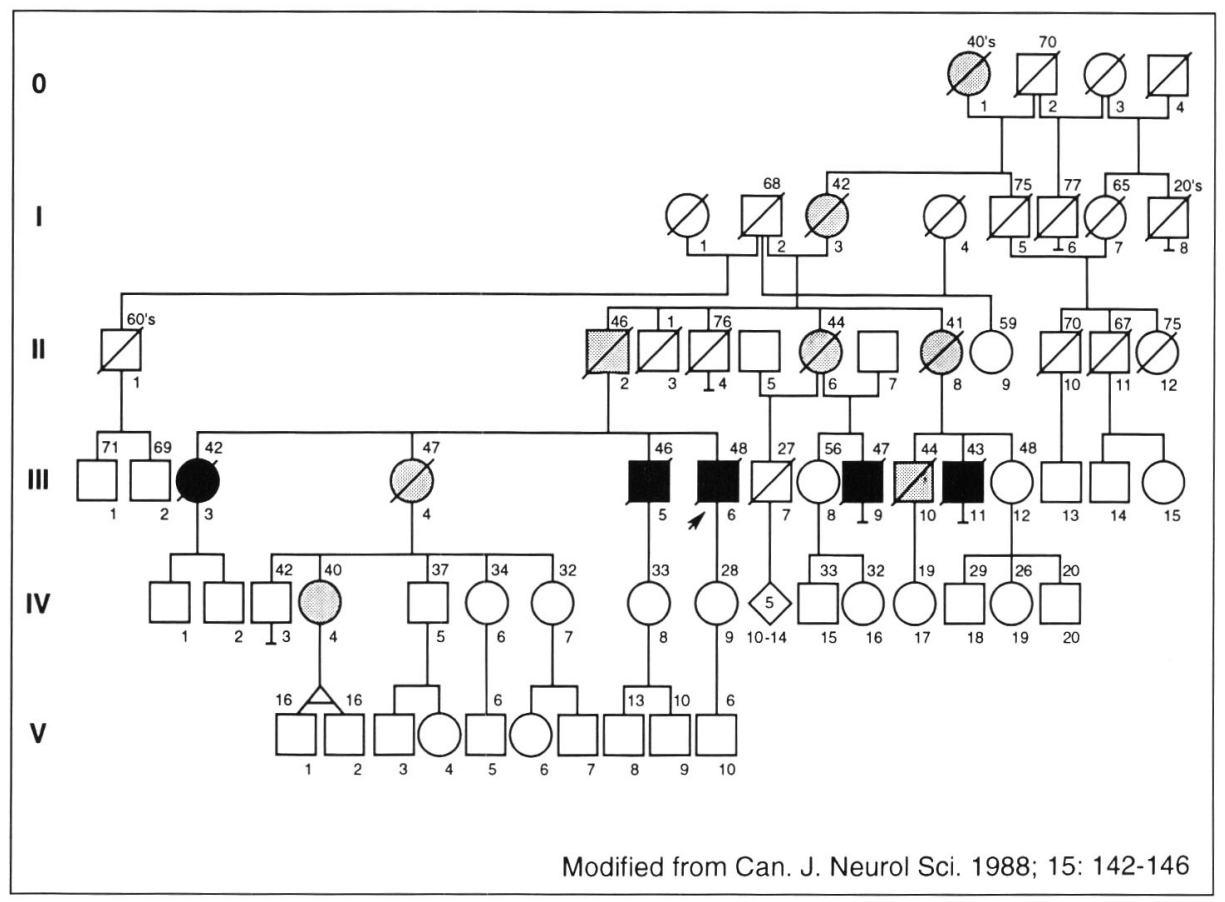

Figure I - Pedigree summary for Patient I (FAD).

Patient 2 initially presented at the Alzheimer Clinic in 1986. Previous psychiatric evaluations (1983 and 1985) had resulted in diagnoses of "schizophrenia", "severe personality disturbance" or "dementia" (Alzheimer type). Of major concern at the time of assessment was an allegation of sexual assault which had been a factor in the marital break-up. Past medical history was unremarkable. Family history was significant for a sister, born in 1934, who had a longstanding diagnosis of Alzheimer disease, following an initial diagnosis of "post-partum" depression.

At initial assessment in the Alzheimer Clinic, Patient 2 was living with his parents and required reminders to perform self-care tasks such as shaving. He was unable to do household chores, prepare meals or handle finances. Marked fluctuations in his daily functioning were reported. Receptive and expressive language skills were intact. No psychiatric diagnosis was made and the neurological examination was unremarkable except for fine postural and action tremor of the hands. CT scan showed evidence of deep white matter changes predominant in both perifrontal regions and extending into the centrum semiovale consistent with a demyelinating disease. No conclusive diagnosis was reached on this assessment but Alzheimer disease seemed "unlikely".

Patient 2 was reassessed in 1987 as his disinhibition, disorientation and impulsive behaviour were major concerns to his family. He was increasingly showing word finding difficulty. A specialized blood work screen for metabolic disorders was ordered and a deficiency of white blood cell (WBC) lysosomal arylsulfatase A (ASA) identified. This was confirmed by finding a deficiency of ASA in cultured skin fibroblasts. A diagnosis of adult onset metachromatic leukodystrophy was made.

Table 2 summarizes the neuropsychological test results over time for Patient 2.

Patient 2's sister was subsequently assessed at the Alzheimer Clinic and was also diagnosed as adult-onset MLD. Her performance on all measures of cognitive functioning was markedly impaired. Her speech was stereotyped and perseverative and she was passive and unable to perform most cognitive tests.

DNA studies were conducted on several family members - see Figure 2 - and Table 3. Patient 2 and his sister were found to have classical metachromatic leukodystrophy of the adult-onset variant. Two of the children of Patient 2's sister (II-3, II-6) and one sibling (I-4) were found to be carriers. As shown in Table 3, ASA levels were measured twice, using the methods of Baum et al. ${ }^{19}$ and Lee-Vaupel and Conzelmann. ${ }^{20}$ Dr. Kappler, University of Bonn, ran a PCR-based assay for the ASA pseudodeficiency allele. ${ }^{21}$ The results were that neither Patient 2 nor his sister had the known ASA pseudodeficiency allele. While the results rule out ASA/ASA- compound genotypes, it is likely that due to the relatively late age of onset in this sibling pair, they have an as yet unknown allele. Work on this is continuing.

\section{Discussion}

The focus of this report is to illustrate the need to consider childhood neurodegenerative disorders presenting as dementia in adults. ${ }^{22}$ Adult onset MLD is one of the disorders associated with white matter disease to be considered in the differential diagnosis of early-onset dementia, particularly when a family history of dementia is present among siblings and the parental mating was either consanguineous or one or both of the parents are either older than the age of clinical onset in their children or one or both of the parents died after the age of onset in their children. The importance of this was emphasized in a recent paper ${ }^{2.3}$ which provided evidence that the first patient of Alzheimer disease ${ }^{2}$ may in fact have been a patient of adult onset MLD.

Although movement disorders are often present in adult onset MLD $^{24-29}$ and the constellation of deficits may bear a striking resemblance to the features typically associated with subcortical gray matter dementia, as summarized by Cummings, ${ }^{30}$ Patient 2 showed only minimal evidence of movement disorder. The most striking features of his clinical presentation were evidence of prominent frontal demyelination on the CT scan and his disinhibited, erratic behaviour. Although he showed evidence of generalized impairment in multiple spheres 
Table 1: Results of Neuropsychological Evaluation over Time Patient 1

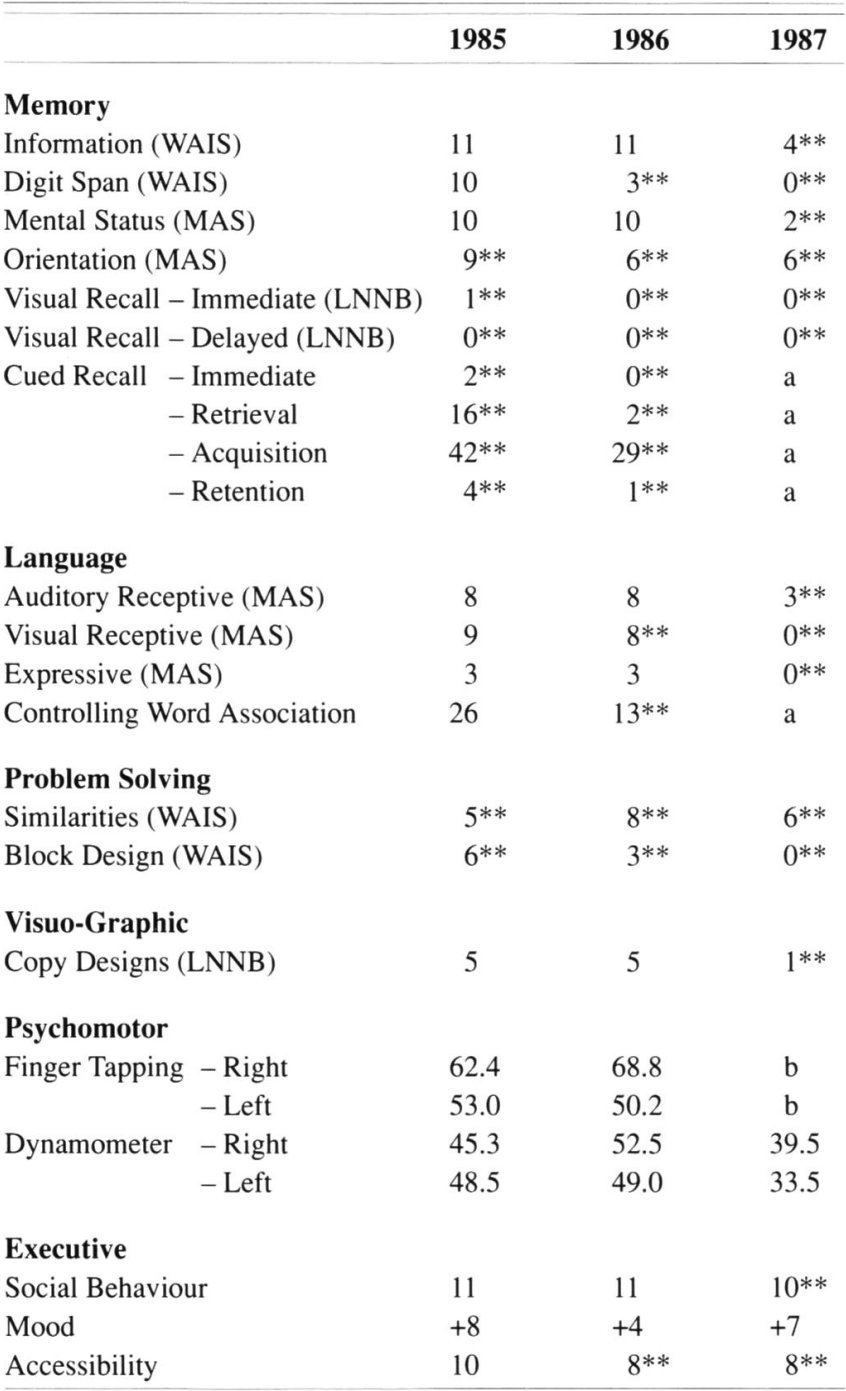

** -Significantly below norm ( -2 standard deviations) for age-related peers $^{46}$

a -Patient unable to perform due to word finding difficulties

b -Patient unable to comprehend instructions

of cognitive functioning, motivation had a definite effect on performance.

Table 4 summarizes similarities and differences between Patient 1 (early onset FAD) and Patient 2 (adult onset MLD). In the context of generalized impairment of cognitive functioning, new learning capacity, as measured by the Cued Recall procedure, ${ }^{16.18}$ was relatively well preserved for Patient 2 in marked contrast to Patient 1 , who showed primarily memory and new learning deficits early in the disease course with deterioration in additional spheres of functioning over time. From 1985-1988, Patient 1 showed a fairly rapid deterioration in cognitive functioning reflecting a pattern consistent with AD. ${ }^{31}$ Patient 2 showed some consistent, though modest, decline in new learning capacity but otherwise had little change in cognitive
Table 2: Results of Neuropsychological Evaluation over Time Patient 2

\begin{tabular}{lrrr}
\hline & 1986 & 1987 & 1990 \\
\hline Memory & & & \\
Information (WAIS) & $4^{* *}$ & $3^{* *}$ & $2^{* *}$ \\
Digit Span (WAIS) & $4^{* *}$ & $4^{* *}$ & $4^{* *}$ \\
Mental Status (MAS) & $4^{* *}$ & $2^{* *}$ & $3^{* *}$ \\
Orientation (MAS) & $9 * *$ & $9^{* *}$ & $9^{* *}$ \\
Visual Recall - Immediate (LNNB) & $3^{* *}$ & $3^{* *}$ & $3^{* *}$ \\
Visual Recall - Delayed (LNNB) & $3^{* *}$ & $3^{* *}$ & $3^{* *}$ \\
Cued Recall - Immediate & $5^{* *}$ & $3^{* *}$ & $3^{* *}$ \\
$\quad 6^{* *}$ & $23^{* *}$ & $17^{* *}$ \\
$\quad$ - Retrieval & 72 & $69^{* *}$ & $58^{* *}$ \\
$\quad$ - Acquisition & 12 & 12 & $10^{* *}$
\end{tabular}

\section{Language}

Auditory Receptive (MAS)

Visual Receptive (MAS)

Expressive (MAS)

Controlling Word Association

Vocabulary (WAIS)

$0 * *$

\section{Problem Solving}

Similarities (WAIS)

Block Design (WAIS)

Object Assembly (WAIS)

Digit Symbol (WAIS)

Visuo-Graphic

Copy Designs (LNNB)

$\begin{array}{lll}7 & 6 * & 8 \\ 9 & 9 & 9 \\ 3 & 3 & 2 * * \\ 9 * * & 7 * * & 7 * * \\ 5 & 5 & 4 * *\end{array}$

Psycomotor

Finger Tapping - Righ

- Left

Dynamometer - Right

- Left

6

$4 * *$

$4 * *$

5

$4 * *$

8

$2 * *$

$3 * *$

$3 * *$

$3 * *$

5

4*

44.4

50.6

49.0

36.0 *

40.0

30.0

29.0

a

42.0

a

Executive

Social Behaviour

Mood

11

$+6$

11

11

Accessibility

10

$+13+$

$+14+$

$8^{* *}$

** - Significantly below norm ( -2 standard deviations) for age-related peers ${ }^{46}$

"+" - Significantly above the norm (+1 standard deviations) for agerelated peers ${ }^{46}$

a - Not administered

functioning. This slow r.tte of decline appears consistent with the history obtained for his sister.

Of interest, both Patient 1 and Patient 2 received psychiatric diagnoses (Patient 1-unipolar depression; Patient 2 schizophrenia) early in the course of their disorders, although these were very different diagnoses. The frequent misdiagnosis of adult onset MLD as schizophrenia has been well-documented. ${ }^{25.32-36}$ Similarly in $\mathrm{AD}$, an initial diagnosis of depression has been reported in the literature. 37.38

For early-onset dementia with a positive family history, accurate diagnosis is critical with respect to risks to other family members. In Patient 1's situation, his daughter and the offspring 


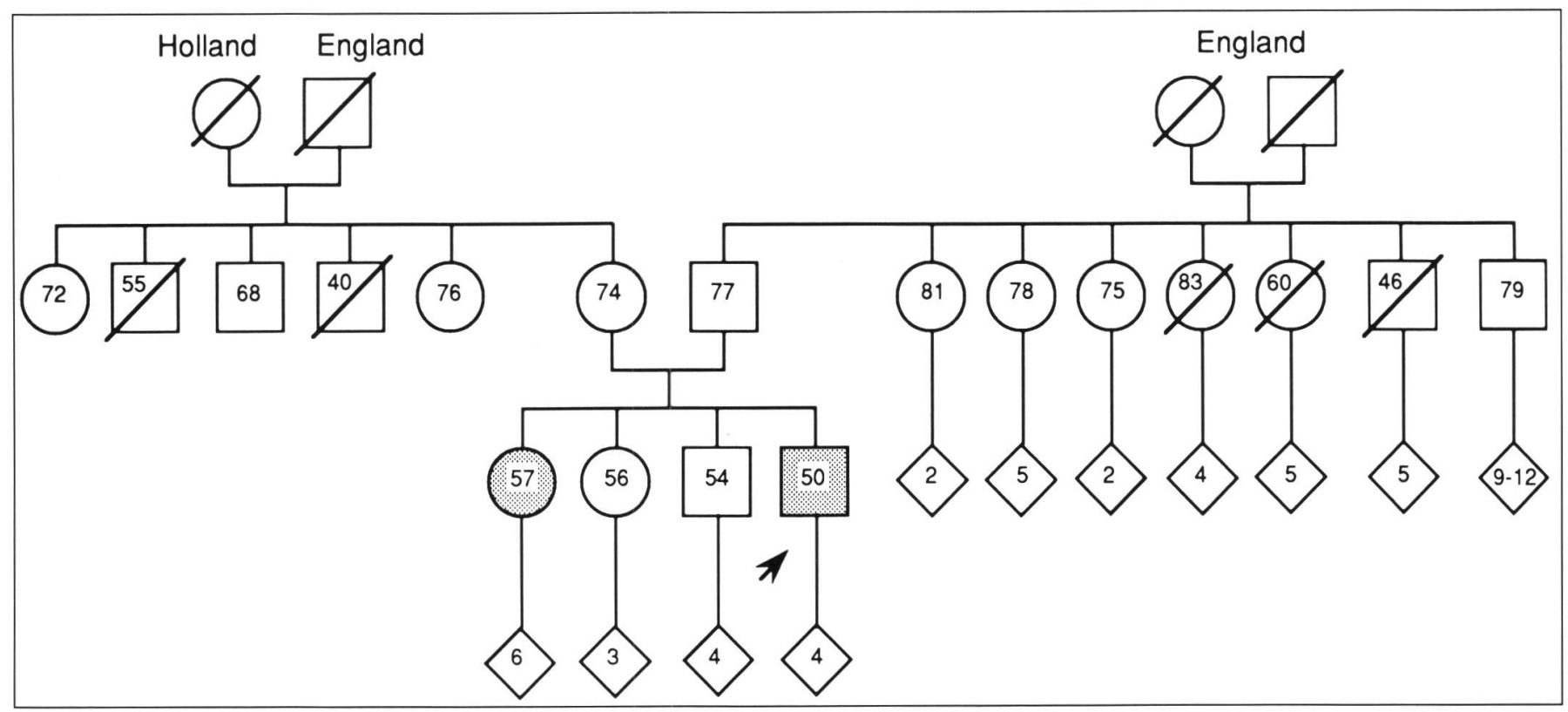

Figure 2 - Pedigree summary for Patient 2 (MLD).

Table 3: Results of WBC ASA Enzyme Studies in Patient 2's Family

\begin{tabular}{ccc}
$\begin{array}{c}\text { Pedigree } \\
\text { Code }^{\mathbf{a}}\end{array}$ & $\begin{array}{c}\text { nmole/hour/mg protein } \\
\text { Baum et al., 195919 } \\
\text { Normal Range } \\
\text { = 55-182 }\end{array}$ & $\begin{array}{c}\text { nmole/hour/mg protein } \\
\text { Lee-Vaupel \& } \\
\text { Conzelmann, 198720 } \\
\text { Controls = 47.8; 39.5; } \\
\mathbf{3 4 . 8 ; 3 0 . 1 ; ~ 6 8 . 6 ; 5 6 . 0}\end{array}$ \\
\hline -1 & 20.3 & 20.2 \\
$0-2$ & 27.8 & 25.0 \\
I-1 & 84.0 & - \\
I-2 & 1.7 & - \\
I-4 & 17.3 & 11.8 \\
I-5 & 8.7 & 1.6 \\
II-3 & 28.2 & 18.9 \\
II-6 & 41.4 & 22.1 \\
\hline
\end{tabular}

"See Figure 2.

of other affected family members have a $50 \%$ risk of developing dementia by their late 30 's, early 40 's. This risk continues from generation to generation, as illustrated in Figure 1. Now that IV4 has developed $A D$, it is particularly significant that her children (V-1, V-2) are monozygotic twins. As the family clearly represents the genetic form of $\mathrm{AD}$, if either $\mathrm{V}-1$ or $\mathrm{V}-2$ develops AD by the early 40 's, the co-twin would have virtually a $100 \%$ probability of also developing the disorder. A 50\% "at risk" status for early onset dementia with fairly rapid progression has an enormous impact on individuals from early-onset FAD families. Molecular genetic studies ${ }^{3.39-43}$ have shown that $A D$, including FAD, is etiologically heterogeneous. Research is continuing to identify DNA markers linked to FAD in families as well as to identify the FAD gene. The potential outcome of this research could result in the possibility of predictive testing for "at risk" individuals in families such as Patient 1's. Although there are no proven therapeutic interventions at this time, there are a number of ongoing experimental trials for AD. Thus the need to recognize it early is more than of "academic" importance.

The genetics of adult-onset MLD are not fully delineated as recent work has suggested that pseudodeficiency allele may exist in some families. ${ }^{6.7}$ Patient 2's family does not have the pseudodeficiency allele. However, in contrast to FAD, there is no evidence for autosomal dominant inheritance in MLD. Autosomal recessive inheritance is most compatible with family histories for MLD and this is clearly indicated in Patient 2's family - see Table 4 and Figure 2. The risks for the subsequent generation are relatively low, unless there is a consanguineous mating. The carrier frequency is estimated at approximately $1 / 800$. Therefore, as II-3 is a known carrier, his risk for an affected child would be calculated as follows:

$$
1 / 2 \times 1 / 800 \times 1 / 4=1 / 6400
$$

where $1 / 2=$ probability of a carrier passing on the disease gene

$1 / 800=$ population gene frequency

$$
1 / 4=\text { probability that } 2 \text { carriers will have an affected child }
$$

The need for careful differentiation and documentation of the various forms of dementia cannot be overstated even though there are presently no proven successful therapeutic interventions for AD or adult onset MLD. Therapeutic approaches may differ markedly depending on the nature of the underlying disorder. For example, bone marrow transplant for treatment of late infantile onset MLD has recently been reported $d^{44.45}$ and MLD may be amenable to interventions that restore the integrity of the myelin sheath. Treatment approaches to AD typically involve attempts to alter the biochemical deficits associated with the disease process (e.g., cholinergic hypothesis). Thus, a clear understanding of the underlying diagnosis in a dementia is necessary if effective treatments are to be identified. In addition, 
Table 4: Comparison of Clinical Features for Familial Alzheimer Disease (Patient 1) and Adult Onset Metachromatic Leukodystrophy (Patient 2)

\begin{tabular}{lll}
\hline Feature & Patient 1 & Patient 2 \\
\hline Sex & Male & Male \\
Year of Birth & 1940 & 1941 \\
Age of Onset & 40 & 40 \\
Duration & 8 yrs to death & 10 years to present \\
Ethnicity & Irish/Scottish & English/Dutch \\
Psychiatric Diagnoses & unipolar depression (age 40) & schizophrenia (age 44) \\
Diagnoses & initially pseudodementia, & initially AD, finally MLD \\
& finally FAD & \\
Family History & suggestive of autosomal & suggestive of autosomal \\
& dominant inheritance - 13 & recessive inheritance - siblings \\
& family members affected & affected, otherwise \\
Overall New Learning Capacity & over 4 generations; & \\
Global Cognitive Decline & deficits noted early on; & relatively preserved, but \\
Aggressiveness/Hostility & deterioration over time \\
CT-SCAN results & relatively rapid & relatively unchanged \\
& progressive & fluctuating
\end{tabular}

Note: Familial Alzheimer Disease (FAD); Alzheimer Disease (AD); Metachromatic Leukodystrophy (MLD)

the genetic implications are clearly different for adult onset MLD and early onset FAD as well as other neurodegenerative disorders presenting as dementia in adults. ${ }^{22}$ Misdiagnosis is a major confounding factor in all research, including treatment trials and molecular genetic analyses.

\section{ACKNOWLEDGEMENTS}

The authors would like to thank Patient $I$ and Patient 2 as well as their families for their cooperation during the ongoing clinical assessments.

Dr. Sadovnick's personal support is, in part, from the Alzheimer Society of British Columbia. This research was funded, in part, by a grant to Dr. Sadovnick from the Alzheimer Society of Canada and, in part, by a summer studentship to Mr. Hadjistavropoulos from the Alzheimer Society of British Columbia made possible by a donation from the International Alzheimer Society.

The authors are indebted to Dr. Joachim Kappler, Institute of Human Genetics, University of Bonn, Bonn, West Germany for having tested family members for the existence of the ASA pseudodeficiency allele.

\section{REFERENCES}

1. McKhann G, Drachman D, Folstein M, et al. Clinical diagnosis of Alzheimer's disease: report of the NINCDS-ADRDA Work Group under the auspices of the Department of Health and Human Services Task Force on Alzheimer's disease. Neurology 1984; 34: 939-944.

2. Alzheimer A. Uber eine eigenartige Erkkrankung der Hirnrinde. Allgemeine Zeitschrift fur Psychiatrie und PsychishGerlichtliche Medizin 1907; 64: 146-148.

3. St. George-Hyslop PH, Haines JL, Farrer LA, et al. Genetic linkage studies suggest that Alzheimer's disease is not a single homogeneous disorder. Nature 1990; 347: 194-197.

4. Fressinaud C, Vallat JM, Masson M, et al. Adult onset metachromatic leukodystrophy presenting as an isolated peripheral neuropathy. Neurology 1992; 42: 1396-1398.

5. Bosch P, Hart MN. Late adult-onset metachromatic leukodystrophy: dementia and polyneuropathy in a 63 -year-old man. Arch Neurol 1978; 35: 475-477.
6. Baumann N, Masson M, Carreau V, et al. Adult forms of metachromatic leukodystrophy: clinical and biochemical approach. Dev Neurosci 1991; 13: 211-215.

7. Gieselmann V, Polten A, Kreysing J, et al. A pseudodeficiency: loss of a polyadenylation signal and $\mathrm{N}$-glyosylation site. PNAS 1989; 86: 9436-9440.

8. Polten A, Fluharty AL, Kappler J. Molecular basis of different forms of metachromatic leukodystrophy. N Engl J Med 1991; 324: 18-22.

9. Sadovnick AD, Tuokko H, Horton A, et al. Familial Alzheimer's Disease. Can J Neurol Sci 1988; 5: 142-146.

10. Fisher NR, Cope JS, Lishman WA. Metachromatic leukodystrophy: conduct disorder progressing to dementia. J Neurol Neurosurg Psychiatry 1987; 50: 488-489.

11. Sadovnick AD, Irwin ME, Baird PA, et al. Genetic studies on an Alzheimer Clinic population. Genetic Epidemiology 1989; 6 : 633-643.

12. Coval M, Crockett D, Holliday S, et al. A multi-focus Assessment Scale for use with frail elderly populations. Can J Aging 1985; 4: 101-109.

13. Wechsler D. Wechsler Adult Intelligence Scale Manual. Psychological Corporation, 1955.

14. Benton AL. Differential behavioral effects in frontal lobe disease. Neuropsychologia 1968; 6: 53-60.

15. Golden CJ, Hammeke TA, Purisch AD. Luria-Nebraska Neuropsychological Battery. Los Angeles: Western Psychological Services, 1980.

16. Buschke H. Cued recall in amnesia. J Clin Exp Neuropsychol 1984; 6: $433-440$.

17. Tuokko H, Crockett D. Cued recall and dementia. J Clin Exp Neuropsychol 1989; 11: 278-294.

18. Tuokko H, Vernon-Wilkinson R, Weir J, et al. Cued recall and early identification of dementia. J Clin Exp Neuropsychol 1991; 13: 871-879.

19. Baum H, Dodgson KS, Spencer B. The assay of arylsulfatase A and $B$ in human urine. Clin Chim Acta 1959; 4: 453-455.

20. Lee-Vaupel M, Conzelmann E. A simple chromogenic assay for arylsulfatase A. Clin Chim Acta 1987; 164: 171-180.

21. Gieselmann V. An assay for the rapid detection of the arylsulphatase A pseudodeficiency allele facilitates diagnosis and genetic counselling for metachromatic leukodystrophy. Hum Genet 1991; 86: 251-255. 
22. Coker SB. The diagnosis of childhood neurodegenerative disorders presenting as dementia in adults. Neurology 1991; 41: 794-798.

23. Amaducci L, Sorbi S, Piacentini S, et al. The first Alzheimer disease case: a metachromatic leukodystrophy. Dev Neurosci 1991; 13: 186-187.

24. Van Bogaert L, Dewulf A. Diffuse progressive leukodystrophy in the adult with production of metachromatic degenerative products (Alzheimer-Baroncini). Arch Neurol Psychiatry 1939; 10: 10631097.

25. Sourander $P$, Svennerholm L. Sulphatide lipidosis in the adult with the clinical picture of progressive organic dementia with epileptic seizures. Acta Neuropathol (Berl) 1962; 1: 384-396.

26. Manowitz $\mathrm{P}, \mathrm{K}$ ling $\mathrm{A}$, Kohn $\mathrm{H}$. Clinical course of adult onset metachromatic leukodystrophy presenting as schizophrenia. J Nervous Mental Dis 1978; 166: 500-506.

27. Scully RE, Mark EJ, McNeely BU. Case records of the Massachusetts General Hospital. Case 7-1984. N Engl J Med 1984; 310: 445-455.

28. Wulff $\mathrm{CH}$, Trojaborg W. Adult metachromatic leukodystrophy: neurophysiologic findings. Neurology 1985; 35: 1776-1778.

29. Merriam AE, Hegarty AM, Miller A. The mental disabilities of metachromatic leukodystrophy: implications concerning the differentiation of cortical, subcortical and white matter dementias. Neuropsychiat, Neuropsychol Behav Neurol 1990; 3: 217-225.

30. Cummings JL. Subcortical dementia. Br J Psychiatry 1986; 149: 682-696. Devanand DP, Nelson JC. Concurrent depression and dementia: implications for diagnosis and treatment. J Clin Psychiatry 1985; 46: 389-392.

31. Reisberg B, Ferris SH, de Leon MJ, et al. The Global Deterioration Scale for assessment of primary degenerative dementia. Am J Psychiatry 1982; 139: 1136-1139.

32. Betts TA, Smith WT, Kell RE. Adult metachromatic leukodystrophy (sulphatide lipidosis) simulating acute schizophrenia. Neurology 1968; 18: 1140-1142.

33. Muller D, Pilz H, Ter Moulen V. Studies on adult onset metachromatic leukodystrophy: I. Clinical, morphological and histochemical observations in two cases. J Neurol Sci 1969; 9: 567-584.

34. Mahon-Haft H, Stone RK, Johnson R, et al. Biochemical abnormalities of metachromatic leukodystrophy in an adult psychiatric population. Am J Psychiatry 1981; 138: 1372-1374.
35. Finelli PF. Metachromatic leukodystrophy manifesting as a psychiatric disorder: computed tomographic correlation. Ann Neurol 1985; 18: 94-95

36. Waltz G, Harik S, Kaufman B. Adult metachromatic leukodystrophy. Value of computed tomographic scanning and magnetic resonance imaging of the brain. Arch Neurol 1987; 44: 225-227.

37. Dulaney JT, Moser HW. Sulphatise lipidosis: metachromatic leukodystrophy. In: Stanbury JB, Wyngarden JB, Frederisckson DS, eds. The Metabolic Basis of Inherited Disease, 4th edition. New York: McGraw-Hill, 1978.

38. Wragg RE, Jeste DV. Overview of depression and psychosis in Alzheimer's disease. Am J Psychiatry 1989; 146: 577-587.

39. Goate AM, Chartier-Harlin CM, Mullan M, et al. Segregation of missence mutation in the amyloid presursor protein gene with familial Alzheimer's disease. Nature 1991; 349: 704-706.

40. Schellenberg GD, Anderson L, O'dahl SO, et al. APP ${ }_{717}, \mathrm{APP}_{693}$, and PRIP gene mutations are rare in Alzheimer's disease. Am J Hum Genet 1991; 49: 511-517.

41. Kamino K, Orr HT, Payemi H, et al. Linkage and mutational analysis of familial Alzheimer disease kindreds for the APP gene region. Am J Hum Genet 1992; 51: 998-1014.

42. Schellenberg G, Bird TH, Wijsman EM, et al. Genetic linkage evidence for a familial Alzheimer disease locus on chromosome 14. Science 1992; 258: 668-671.

43. Pericak -Vance MA, Bebout JL, Gaskell PC, et al. Linkage studies in I'emilial Alzheimer's disease: evidence for chromosome 19 linkage. Am J Hum Genet 1991; 48: 1034- 1050.

44. Krivit W, Shapiro E, Kennedy W, et al. Treatment of late infantile onset metachromatic leukodystrophy by bone marrow transplantation. N Engl J Med 1991; 322: 28-32.

45. Schapiro EG, Lipton ME, Krivit W. White matter dysfunction and its neuropsychological correlates: a longitudinal study of a case pf metachromatic leukodystrophy treated with bone marrow transplant. J Clin Exp Psychol 1992; 14: 610-624.

46. Bealtie BL, Tuokko $\mathrm{H}$. Cognitive functioning in senior citizens. Bluma Tischler Post-Doctoral Fellowship Report, University of British Columbia, Faculty of Medicine, 1985. 